Title:

\title{
Employability as an Ethos in Translator and Interpreter Training
}

Authors:

Claire Cuminatto (lead author), Roger Baines and Joanna Drugan

Affiliation:

School of Politics, Philosophy, Language and Communication Studies, University of East Anglia, Norwich, UK

Contact details:

School of Politics, Philosophy, Language and Communication Studies, Arts Building, University of East Anglia, Norwich Research Park, Norwich NR4 7TJ

+44 (0)1603 456161 (main UEA switchboard)

c.cuminatto@uea.ac.uk, r.w.baines@uea.ac.uk, j.drugan@uea.ac.uk

Acknowledgements:

We wish to thank Charlotte Burford of the Alumni Office at UEA for her assistance in preparing and analysing the survey reported here, and all the students and alumni who contributed to our research. We are also grateful to all those colleagues whose modules and 
work we discuss in this article, particularly Carlos de Pablos-Ortega, Marie-Noëlle Guillot and Claudine Tourniaire. 


\begin{abstract}
'Employability' is now a key term in university strategies in the UK and increasingly across Europe. Pressure to implement such strategies can lead to bolted-on rather than embedded activities within academic curricula. This paper argues that employability should be an embedded ethos for translation and interpreting courses in particular. Employability can be addressed effectively by using real world applications of learning, to enrich the discipline but also to provide distinct types of intellectually stimulating content. The University of East Anglia has a long history of this approach. This paper outlines case studies of effective practice at Masters and undergraduate level, including modules where students collaborate on translations for real clients. Such an endeavour poses important challenges, both logistical and ethical: how can we expose students to real-world contexts without taking work away from professionals? This issue can be unwisely ignored or a source of academics' reluctance to engage in such activities. Using original data from a recent alumni survey and semi-structured interviews, we map the outcomes of such an ethos. We ask whether engaging in real-world oriented activities as students affects the professional paths of alumni, both in the translation/interpreting industry and in other sectors.
\end{abstract}

\title{
Keywords
}

employability, ethics, interpreting, translation, professional practice, transferable skills 
'We empower our students for the world of work'. This is the fifth of seven strategic objectives in the University of East Anglia's corporate plan for 2012-2016 (University of East Anglia, $[2011,6])$, an idea which can no doubt be found in many other universities' plans across and beyond Europe.

The foregrounding of students' employability development in the Higher Education (HE) sector is the latest result of a concern which employers expressed in the UK as early as the 1980s: to them, graduates leaving universities were lacking crucial vocational skills (Kearns 2008, 202). Governments responded by exhorting universities to act in order to improve graduates' skill-sets. For example, the 2005 Australian government made the development of graduate attributes statements a condition for public funding (Green et al. 2009, 18). Some larger employers attempted to take the matter into their own hands, including the European Commission's Directorate General for Translation, which created the European Master's in Translation certification process in 2006 in a bid to encourage participating institutions to provide MA students with a skill-set that would "meet agreed professional standards and market demands"

Yorke's widely adopted definition of employability is consistent with this industry-born vision, as it explicitly features the need to benefit the workforce and the economy in general. Employability is "a set of achievements - skills, understanding and personal attributes - that makes graduates more likely to gain employment and be successful in their chosen

\footnotetext{
${ }^{1}$ DG Translation. ND. "European Master's in Translation.” European Commission. Accessed June 32016. http://ec.europa.eu/dgs/translation/programmes/emt/index_en.htm
} 
occupations, which benefits themselves, the workforce, the community and the economy" $(2006,8)$.

What are the "skills, understanding and personal attributes" that Yorke mentions? We will, in this article, focus on vocational skills, which are related to a specific profession (in the context of translation studies, these could for instance include a command of ComputerAssisted Translation tools), and transferable skills (also called 'graduate attributes', 'core' or 'generic skills'), which Kearns defines as preparing students for mobility between a number of different jobs (ibid., 201); of course some skills can be both vocational and transferable. There is a lack of conceptual clarity around the idea of transferable skills (Peverati 2013, 1), lists of which, according to Pym (2009), are often a "discourse of accumulated opinion" rather than the result of empirical research. However, whatever they are called and even if inconsistencies remain, no one can argue that in today's volatile job-market, adaptability is not crucial to survive and thrive. Many students who complete a degree in translation or interpreting will not become translators/interpreters, nor even work with languages. As Straby pointed out as early as 2002, "Work is now not defined by occupational titles or categories, but by skills and values. Effective career builders know how to shape and build their careers, project by project" (in Kumar [2007, 15]).

How can translation and interpreting programmes help students to become 'effective career builders', developing both vocational and transferable skills? A 'quick-fix' answer to this question would be a bolted-on approach, with employability-related activities separate from the curriculum. Such a strategy runs the risk of students categorising employability as unimportant or optional, and therefore opting out of proposed activities. The strategy 
recommended by most HE professional institutions (such as the Higher Education Academy in the UK) is to embed vocational and generic skills-acquisition into programmes. Past research such as that by Kember et al. $(2007,12)$ has demonstrated that teaching which aims for students' understanding and active involvement is one of the main factors in what they call 'capability development', thus underlining that the employability agenda should not be at odds with the already time-challenged translation and interpreting course curricula. The idea is not to completely change or add to already existing activities, but to enrich them by perceiving them through another lens.

Kumar's 2007 SOAR model of employability outlines four different stages of career decision making, i.e. Self-awareness, Opportunity awareness, Aspirations and Results. Opportunity awareness (exploring the options open to oneself) and Results (the ability to implement one's choices, via job-search skills, for example) are crucial and cannot always or exclusively be tackled within modules. But as we have seen, it would be a mistake to believe that they represent the full employability picture. This is why a department's close relationship with the central Career Services of its university is of prime importance so that Careers Advisers' expertise supports and complements what is being done in the curriculum. Our approach therefore combines both fully embedded and co-curricular activities, as we believe the two in combination answer different needs in students' career decision-making.

At UEA, the link between academic departments ('Schools') and Careers Services is ensured by dedicated Employability Directors (EDs). This role was born out of previous Careers Liaison Officer and Employability Champion roles (the shift in semantics is revealing in itself). From 2012-13, each School has been required to appoint an academic to this role. The 
School of Language and Communication Studies went further by allocating an employability budget and teaching buy-out. However the real institutional 'push' occurred when all academic EDs were given a $40 \%$ teaching buy-out in 2014 . This reflects increasing recognition that time needs to be devoted to the issue inside Schools, as well as within central Career Services. The ED role entails setting up and implementing a School Employability Plan, and taking part in Executive and Teaching committees to ensure that Employability remains at the forefront of teaching and managerial decisions, as well as organising and running initiatives and activities within the School in collaboration with central Career Services.

Increasing institutional support for employability built on the earlier development of a focus on translation and interpreting in UEA's language degrees, including significant investment in the necessary interpreting and translation facilities. Up until the early 2000s, UEA's degrees were relatively traditional Area Studies programmes with a focus on the study of literature, history and politics alongside core modules to develop language proficiency. Our translation and interpreting programme was already in place and, as the translation industry became more and more significant in line with the development of internet-based business and professional communication, we began to embed translation studies across the undergraduate curriculum. Since the mid-2000s, we have oriented our undergraduate and postgraduate courses towards contemporary communication with a focus on translation, interpreting, and intercultural communication. The purpose of this reorientation was twofold: to establish ourselves as distinctive in the UK HE market and to reflect staff research interests. Consequently, most of our degree programmes include the study of translation and/or interpreting focused modules. These can either be as compulsory elements of the curriculum: Translation and Interpreting; Translation, Media and Honours Language(s) (both undergraduate with one or two of French, 
Spanish, Japanese), and the MA in Applied Translation, or as electives: Modern Language(s); Intercultural Communication with Business Management (both undergraduate); and the MA in Global Intercultural Communication.

This reorientation was initially at module level, through such modules as Translation Issues in the Media, and Translation Work Experience, then later at programme level, such as those in Translation, Media, and Honours language(s). Simultaneously, we launched a Masters in Applied Translation Studies in 2003 which remains distinctive because it does not restrict recruitment to specific language pairs but instead offers language pair-specific assessment, support and mentoring from practising translators who are recruited via professional bodies and high-quality translation agencies with whom we have built a long-term relationship. With a framework of translation programmes and modules in place, we were able to incrementally build up career-focussed events relating to translation and interpreting.

This article argues that there are benefits for curricula, students and graduates when we embed transferability as an ethos, rather than seeing employability as an add-on. In order to map the outcomes of such an ethos, we report original research and a series of case studies.

\section{Methodology}

Quotes and figures presented in this article relate to data collected via a 2016 survey of alumni and follow-up interviews. The University’s Alumni Office distributed an email invitation to complete an online questionnaire on behalf of the authors. This was delivered to 979 graduates of UEA undergraduate and MA degrees over a period of two weeks, and followed by two automatically generated reminder emails. The response rate was $68 \%$, which 
significantly exceeds email survey response rates generally (Nulty 2008, 301). A series of paired questions asked first about participation in particular modules and employability events during respondents' academic career at UEA, then a second question asked them to identify the transferable skills they took from these modules and events. Skills were selected from a list of attributes devised by the University, or entered by respondents as free text. After initial analysis of the survey results, we conducted three semi-structured interviews with a current student, a recent graduate, and an alumnus who graduated over a decade ago to enable comment on the effects of the training on professional experience. We selected these interviewees by inviting anyone in these groups willing to undertake a semi-structured interview with availability during the research period to contact us. The interview participants were then selected to reflect a representative sample relating to the case studies across the different degree programmes, language pairs and levels of experience. A summary of the responses to each of the questions in the survey is reported below, including some verbatim comments (in italics) taken from free text boxes included in the questionnaires, and from comments made during the follow-up semi-structured interviews. We use these responses and comments to understand whether the real-world oriented activities engaged in as students had an impact on the professional paths of alumni, whether these lie in the translation/interpreting industry or not. We also review tried-and-tested examples of effective practice at Masters and undergraduate level via a series of case studies, and draw out wider ethical aspects involved in embedding employability as an ethos across programmes. Via three case studies we will also focus on how and where employability has been embedded into the following: the undergraduate and postgraduate module Translation Work Experience; the undergraduate translation and interpreting degree programme (two languages from French, Spanish and/or Japanese); and modules within the MA in Applied Translation Studies. Survey and interview responses will be analysed within these case studies. 


\section{Case Study 1 - Translation Work Experience Module}

Translation Work Experience (TWE) is only one of many modules which could have been presented here as an example of our employability ethos; others include Technical Tools for Subtitling and Dubbing, Introduction to Conference Interpreting or Translation as a Profession. TWE was selected as the longest-running example of our approach because this allows us to discuss how the teachers of such modules must themselves be prepared to be adaptable in response to changing circumstances. This innovative module was created by Marie-Noëlle Guillot in 2001 for undergraduate students, and was quickly followed by a postgraduate version. The module gives students the opportunity to work jointly on professional translation briefs provided by local or international partners (generally small museums with no resources for translation services which can provide a large and diversified range of source texts). These partners are mostly found through the module organiser's personal contacts, although occasional prospection has had to take place to reflect the growth in languages required. The module is not language specific; this helps rationalise teaching resources and ensure good enrolment. It is therefore likely that groups will work from or into at least four different languages in the same seminar. The teaching is 'hands-on': there is no lecture, and relevant translation theory is provided via other co-taught modules and in targeted reading on the advice of the module leader. This module was born out of the greater vocational orientation of our academic programmes, and more particularly out of the wish to respond to professional concerns (challenges involved in translating to client specifications; producing and delivering a product which conforms to professional standards; learning to manage reference materials, etc.) (Guillot 2014). 
During the first half of the semester, the client briefs are introduced, organisational issues tackled, diagnostic exercises completed, and aspects of professional translation (such as resources, terminology management tools, research methodology) discussed. Students also start working on their translation. The second half is spent working on the briefs, with individual or small group tutorials, and presentations reviewing progress and issues, where peer feedback is central. The postgraduate version of the module is naturally more demanding with additional student input, including a report on comparative 'experiments', such as working on a translation with and without CAT tools to evaluate their impact on translation workflow, efficiency, consistency and quality. The summative assessment pattern of the module is twofold. The first part is an extended translation which is longer and more complex for postgraduate students and has to be submitted two-thirds of the way through the semester. Students then receive feedback from a professional translator for their language pair/direction and must submit a revised version of their work by the end of the semester. In order to enhance and reward students' ability to reflect on their learning and progress, the translation part of the assessment represents only $30 \%$ of the overall mark for the module, while $70 \%$ is attributed to individual reports. These reports tackle some academic aspects (such as a detailed analysis of chosen passages or a list of resources and their critical analysis), but significantly, also require reflection on the overall process. Beyond the invaluable practical experience gained by students, the employability value of the module lies in this reflective piece based on a week-by-week diary, as it encourages students to formulate their strengths and weaknesses, and think about the process rather than the end result alone.

There are invariably many transferable skills to reflect upon, as students have to show professionalism in order to reach industry standards (good is not good enough!) and are responsible for key organisational matters, such as creating the groups or splitting the 
translation work. Being a good team player is therefore a crucial aspect. This was recognised by the alumni who completed the survey: $67 \%$ of the students who took modules with clear vocational skill outcomes (such as TWE) indicated that the work undertaken had a positive impact on their team working and leadership skills. The importance of negotiation, as well as giving and receiving feedback was particularly stressed by one of the respondents:

In Translation Work Experience, I was paired with somebody whose translation strategies were polar opposites to mine... I took a chunk, s/he took a chunk and we sat down together to hash out the final chunk... However, as there was so clear a division, to ensure the target text's coherence, we eventually had to go through the entire thing and find something of a middle ground (and I am proud of the final product!). This experience has served me well - having to give and accept constructive criticism; having to look at my own work in a new light, and accept that my approach was not necessarily the only valid one, or indeed the best one; ironing out inconsistencies when two or more translators work on a project.

Although this comment relates to a translation task, its application to many other professional contexts is evident. One of the respondents, for example, reported working in the quality and training department of a large organisation, where s/he is constantly required to praise and provide constructive criticism to colleagues. Problem-solving was another highly rated skill: $59 \%$ of the alumni who had taken modules with clear vocational outcomes indicated having developed strategies such as tackling "difficult chunks of a text by breaking it down and looking at it in practical ways". Interesting examples of transfers into non-translation sectors were highlighted repeatedly by respondents, such as a representative of a global company who has to be able to demonstrate “quick problem solving regarding customers' purchase orders and deliveries". 
TWE is a pioneering module which is very representative of our Employability ethos, something recognised by graduates of the module: "Taking the Translation Work Experience module, in which we were able to translate professionally, gave me a platform to launch my translation career". Students' professionalism is put to the test throughout, and transferable skills are consciously developed thanks to the ongoing reflective work required in the module's assessment pattern. However, this work at module-level would be insufficient if it were not supported by an employability-proactive course strategy, which is the focus of the second case study presented here.

\section{Case Study 2: UG degree programme Translation and Interpreting}

This degree course began as an interpreting and translation programme in the late 1980s in response to student enthusiasm for advanced special subject interpreting and translation modules and academics' growing awareness of evolving industry needs as technology and globalisation affected both market demand and the skill-sets needed to work in the fields. The course has evolved to reflect: national student demand for particular language pairs and local expertise - French and German and Scandinavian languages until the mid-2000s, then French and Spanish until the addition of a new language, Japanese, in 2012; and the expansion of the translation and interpreting industry. The degree programme requires students to take two languages to degree level and take translation and interpreting modules which provide its vocational core.

1. Translation and interpreting skills are embedded in core language teaching in years one and two as part of language competence modules but also by pairing students starting a degree language ab initio with advanced students who interpret foreign language lectures for them, in the case of Spanish. This provides an obvious 
example of effective transfer related to interpreting activities: "Interpreting for $A b$ Initio students meant preparing, focusing and communicating effectively, skills that were useful when I later did simultaneous interpreting for Doctors of the World conferences". The year/semester abroad offers the opportunity for additional training at prestigious translation and interpreting centres such as ISIT, the Institute of Intercultural Management and Communication in Paris, the University of Geneva, and the University of Salamanca while the final year provides specialist translation and interpreting modules.

2. In terms of interpreting, the modules on offer have grown in number and become more specialised to reflect the development and recognition of professional public service interpreting as well as conference interpreting. The vocational training provided in introductory modules in Conference Interpreting and in Public Service Interpreting can only be introductory because entry into professional interpreting jobs requires at least a Masters level qualification plus a significant number of hours of personal practice. This serves as an example of how students can be helped to appreciate the level of their skills, a valuable awareness that is transferable to all kinds of skills in all kinds of contexts. The in-class interpreting training is complemented by talks from practising interpreters as part of our In Other Words public talks series, with prestigious speakers from, for example, the Association of Police and Court Interpreters and the French Parliament. In addition we provide a series of visits to professional organisations, and workshops run in professional contexts. For example, students undertake regular accompanied visits to Brussels and Paris where they meet and observe conference interpreters in places such as the European Parliament/Commission or the Organisation for Economic Co-operation and 
Development (OECD). As referred to at the beginning of the article, what Kumar (2007) calls 'Opportunity awareness' (exploring the options open to oneself) and 'Results' (the ability to implement one's choices, via job-search skills for example) cannot always be tackled within modules. In this context, it was notable that 'Career Management skills' and 'Commercial Awareness' were among the highest rated items in the questions related to co-curricular activities (55\% and $41 \%$ respectively in the question on study and employability visits, and $43 \%$ and $46 \%$ respectively in the question on employability events and talks), while they were selected less often in module-related questions, hence demonstrating the complementarity of the two types of activities.

Respondents highlighted that employability-related events, trips and talks were 'eyeopeners' on various levels (discovering the wide range of career options open to them, what languages are/are not in demand, what a 'day in the life of ...' may be like etc.) and therefore helpful in their decision-making process when deciding on future career paths. One alumnus, for example, stated that the "Brussels trip (and accompanying personal development tasks) were genuinely game-changing". The 'personal development tasks' mentioned here refer to guidance points given by the ED at the beginning of employability visits; these are followed up via the submission of reflective pieces of writing by participants at the end. Considering how little or how much an organisation's values match one's own is an important part of this reflective process, as students too often think of recruitment as one-sided. Public service interpreting is supported by extra-curricular activity which encompasses regular visits to observe interpreters at the Norwich Magistrates and Crown Courts. We also coorganise inter-professional communication skills training sessions with the local 
James Paget University Hospital, and Norfolk and Norwich Hospital in the context of the School's Professional Practice scheme (an initiative started to encourage more Module Organisers to try such activities by providing logistical support and industry contacts). Two comments demonstrate how skills beyond interpreting itself were absorbed through these extra-curricular interpreting activities, and applied by our graduates: "I felt that the interpreting workshop at James Paget hospital with junior doctors and other healthcare professionals helped me in several skill areas, not least interpreting"; and "I really enjoyed interpreting as it was more vocational than essay based modules. The hospital trip was very eye opening, especially talking to doctors and hearing their perspective. I think interpreting helped me to think on my feet, adapt quickly and problem solve."

3. In specialised translation modules, students work with a range of text types (e.g. business, technical, news, and commercial websites) which sensitise them to the variety of texts with which professional translators work. These modules are complemented by others such as Translation Issues across Media which explores practical and ethical concerns faced by professionals. We also introduce students to the theory and practice of subtitling and dubbing through a pair of modules, exposing them to examples of professional software such as WinCaps; teaching is enhanced by visits to subtitling and voiceover companies such as Ericsson. Familiarity with particular tools provides the platform for students to be adaptable: "The subtitling module I took taught me how to use time codes. On a subsequent subtitling internship, I didn't use the same software but I was able to adapt and although I wasn't asked to use time codes I incorporated them. I would have been a fish out of water without that knowledge." 
As with interpreting, we expose our students to professional translators via Masterclasses, a series of translation workshop talks from professionals on a wide range of specialisms as well as the nuts-and-bolts of in-house and freelance translation and visits to leading employers such as the DGT in Brussels. Consistent and sustainable contact with alumni is invaluable in the links and relationships that have benefitted our students: I benefitted more than once from UEA alumni passing on job opportunities via the School and have done the same myself so these networks of privileged contacts have been really useful.

According to a 2014 survey of nearly 3,000 companies, 57\% of firms believe that graduates lack a core of soft skills (e.g. communication skills) when they enter the working world (British Chamber of Commerce, 2014²). Broader employability training works in conjunction with modules to support the mapping out of skills and values in relation to what is on offer on the market. One respondent indicated that his/her course was helpful in so doing: "My modules showed me aspects of different career paths and helped me make decisions about what I wanted to do in the future, showing me my weaknesses and strengths, as well as what I enjoyed or didn't." Jobsearch skills, such as CV writing, interview techniques, online profile-building or networking skills, were other aspects quoted several times in the questions about employability talks, events and workshops, which benefit from the fruitful

\footnotetext{
2 ."Young people need more support to make transition from education to work, says BCC." British Chamber of Commerce. Accessed June 12016. http://www.britishchambers.org.uk/press-office/press-releases/young-people-need-moresupport-to-make-transition-from-education-to-work,-says-bcc.html
} 
collaboration between the School and Careers Services.

4. We refer above to specialist translation and interpreting partner institutions for the year/semester abroad. Residence abroad is a critical component of most UK language degree programmes, and a number of respondents considered the year abroad aspect of their course as having provided employers with evidence of problem-solving skills and flexibility. In several comments, having spent time abroad and acquired an indepth intercultural understanding of a country (in and outside modules) was deemed a great asset. This experience can, for example, generate business in foreign markets, or ensure that cultural adaptation and localisation processes are in place: "When I'm creating marketing in French [...], I have a deeper understanding on how to lay it out and present it".

Across the survey, good written and oral communication skills consistently received high scores. Writing skills, to start with, were deemed to have opened the door to a first entry-level job in marketing by one respondent, while another stated that their attention to detail is highly rated by their peers, something which translates in practical terms into a lot of proof-reading work. More specific writing skills and related knowledge were mentioned by other respondents, such as terminology (for an alumnus working in the field of standardisation), and précis-writing skills (in the field of copywriting). Oral communication was also highly rated amongst respondents. Many other comments throughout the survey point to the fact that the effective transfer of skills may take place when having to communicate with the various stakeholders of an organisation (customers, other departments etc.), or having to pitch and assert one's own voice. Our UG degree programme Translation and Interpreting aims to 
provide students with a solid skill-set which they will be able to transfer to any career, whether or not they decide to pursue employment in the translation or interpreting sector:

All the translation talks and employability training opened my mind to the different places a language degree could take me, not just translation or interpreting. It made me look at what skills I do have and what I can bring to the table rather than just language.

For those who do want to become in-house or freelance translators, our MA in Applied Translation Studies, which will be our final case study, ensures that more technical vocational skills are in place by the time students graduate.

\section{Case Study 3: MA in Applied Translation Studies}

This programme started in 2003 to equip students with an understanding of translation theory alongside the skills to work in the rapidly evolving translation industry. Theory and employability complement each other in that skills developed in the former, whether through synthesising complex material into sophisticated arguments and/or applying translation theory to professional contexts, are important professional attributes. The MA is structured to provide three specialist pathways, made possible by a range of core and optional modules. These pathways are: professional translation; forensic linguistics and translation (translation when witnessing, experiencing or judging crime) for which the visits to observe court interpreters described above are particularly relevant; and intercultural communication. We focus here on employability training within core modules and in the professional translation pathway, and extra-curricular events. As described above, rather than restrict recruitment to specific language pairs, this programme offers language-specific assessment, support and mentoring within particular modules from professional linguists. This embedding of explicit cooperation with industry professionals provides students with exposure to industry standards 
as well as the opportunity to develop fruitful mentor/mentee relationships during their studies. It can be seen in the optional Translation Work Experience module presented above but is also a feature of the core module Translation in Context where students develop a portfolio of translations covering a range of text types. This portfolio is then assessed by a professional translator who comments in detail on the first 200 words with spot-checking on the rest of each text thus replicating a typical approach to quality assurance in the translation industry (Drugan 2013). The exercise is completed via a Skype call during which the professional translator and student discuss the texts. The second core module where exposure to similar real-world translation contexts is provided is Technological Tools for Translators. In addition to learning how to use, and compare critically, a range of standard industry software, students undertake group projects where they work in multilingual teams for a project manager and client. Working with students at universities in other countries through partnerships established by the module leader, they learn to negotiate differences in culture and develop effective email communication strategies across time zones, skills which are essential when working in the translation sector (Kenny 1999). In our survey, one technical skill which clearly emerged as important to many alumni in a translation-related career related to digital literacy. The words 'software' and 'Trados' appeared 16 times in the comments, several times to state that having a knowledge of industry-specific pieces of software was a major competitive advantage when applying for jobs: "Many of the positions advertised require experience using tech-tools, which the course provided me with, and which has been a massive help to me in my career." Being able to work with the same software they have learned as students cannot be guaranteed, and tools evolve constantly, so the module aims to build students' confidence and resilience when they encounter new tools in future. Survey respondents acknowledged that possessing such technical skills had allowed them to be more adaptable: "The skills are also easily transferable to similar software package[s]". In 
addition, a range of optional modules include Translation as a Profession which fosters specialised knowledge of the translation profession and adapts each year to students' intended career paths, so they are equipped to start work as soon as their studies are over: "Thanks to my MA training I can understand a bit higher above, see the whole process of translation not only the text. From Translation as a Profession I can learn the broader points of view of a project and the process which benefits me." Our programme of visits to institutions such as the DGT in Brussels and the Translation Masterclasses and In Other Words talks series described above to which practising translators contribute provide an extra-curricular employability layer to the MA's modules. One respondent indicated how effective one talk was in informing and influencing his/her professional orientation:

The talk about Project Management at a translation agency helped me to see in a very real way how the translation classes I was taking at uni have practical application in the working world. This inspired me to work hard in class, and also to find an internship in the translation industry.

Mutually beneficial relationships with translation agencies have proved especially effective. In return for helping identify suitable graduates for internships or freelance work, agencies provide students with those internship opportunities and with detailed information about the industry from the inside in ongoing contributions to our training via talks and participation in seminars, such as for the Translation as a Profession module. In one such enthusiastically received collaboration, an agency head took part in role plays, with students playing the role of freelance translators who were being phoned with the offer of a translation assignment. The professional posed questions which freelance translators would actually be asked in real encounters, and demonstrated a range of approaches which might be used to take advantage of naive providers; this equipped students to be prepared before their first real negotiation. 
Recently, with one local agency, Integro, we have set up a scheme where students will be given the opportunity to undertake translation work for charities. The students gain direct experience of working through an agency, including professional revision and feedback on their work from a specialist for their language pair, while the charities get translation work for which they could not afford to pay. The agency values the opportunity to spot 'rising stars' for future collaborations, and to develop its staff's contribution to corporate social responsibility and wider society.

We would not wish to suggest by this brief summary of the benefits of this ' $360^{\circ}$ ' approach to employability that it is a straightforward matter to embed an ethos across programmes. The challenges are many and ongoing. We consider the two main types of challenge, logistical and ethical, now.

\section{Challenges: Logistical}

In the development of programmes and modules focused on contemporary communication, translation, interpreting and intercultural communication, the logistical challenges have been interlinked. Macro level logistical challenges principally concern staffing and student recruitment, where the former depends on the latter. Consequently, at undergraduate level our approach was one which we termed a 'viral' approach i.e. we introduced the modules first as electives onto existing degree programmes and, once they were established and it was clear they were viable, we had a credible argument and evidence that we should set up degree programmes which had these modules as core elements. The degree programmes then developed in their own right and we were able to embed employability in modules and in events, with both elements developing hand in hand and organically. 
The ' $360^{\circ}$ ' ethos was only successfully implemented once a formal academic role with teaching relief was established to drive and monitor its success. The commitment to this role brought with it the capacity to develop a whole range of employability focused strategies and events. Establishing employability events, and getting students to attend, throws up more micro level logistical challenges such as managing the constraints of university administration (e.g. timetabling) and reaching significant numbers of students across different curricula when smaller more targeted sessions tend to be more successful. A range of approaches have been tried out and range from offering employability events with no requirement for student commitment, offering employability events which oblige students to register and pay a returnable deposit, and making employability events a formal part of modules. Getting the balance between these approaches is crucial to engaging students and avoiding perceptions of overkill. A gradual change in culture in terms of student attitude to the need to engage with internships and employability opportunities has made a difference. This change in culture has been led by the tone of commitment to employability set by the School. Although there are multiple factors beyond the control of institutions when it comes to quantifying graduate employment statistics (what is measured and the volatile market for graduates being but two of these), we experienced a significant increase in our employability figures in data released in 2016 which seems to suggest that embedding employability as an ethos is paying off. A key element in the success of our approach has been regular dialogue, shared initiatives, and collaboration with both the students themselves, but critically also with an appropriately equipped Careers Centre, the staffing of which has increased as employability rose up the institution's agenda. Long-term links with alumni established in their careers have been another crucial element in making events work, arranging mentors, and in securing access to internships and visits to professional premises. 
Formal support among senior management for the attempt to embed employability as an ethos is significant as many of the approaches developed may come into conflict with standard and long-established institutional norms. A range of logistical challenges are likely to be encountered in this new kind of approach and it can only thrive long-term where there is highlevel endorsement and willingness to reconsider standard approaches. Previous work in Translation Studies has recognised some of these challenges, notably around the teaching of 'vocational skills' in the academy (Mitchell-Schuitevoerder [2010, 127]). We have found such logistical challenges particularly apparent around assessment (e.g. timing, coordination with non-assessed embedded activities, weighting, new methods and approaches, supporting group assessment, payment for external expert input) and staffing. This approach requires established and relatively inflexible large institutions to react in a nimble and flexible way, to commit to monitoring and recognising when a new initiative is not working then equally commit to providing resources to address such setbacks.

Perhaps most significantly, embedding an employability focus needed staff buy-in and a shared strategy. Staff buy-in depends on the commitment of staff to a range of challenges such as: the adaptation to different teaching methods; the adoption of new teaching areas and commitment to develop the requisite skills, perhaps outside one's comfort zone; the considerable investment of time needed to identify translation briefs with museums and other organisations and to establish strong links with alumni and translation agencies; the development and maintenance of these relationships; the identification, assessment of the suitability of, and training of professional translators employed to assess practical work; and the maintenance of excellent relationships with alumni so we can monitor the success or gaps in our employability strategies on an ongoing basis. Success depends on the time and energy colleagues are prepared to devote to this work, and particularly on the relationships that 
colleagues develop with external collaborators. All of the above also demands significant staff flexibility, which has the beneficial consequence of providing an example to students of the value of flexibility in the workplace; but which itself presents additional challenges, both logistical and, as we shall explore next, ethical.

\section{Challenges: Ethical}

Embedding employability as an ethos raises concerns about how this can best be achieved in a context of already densely packed academic curricula. Previous work in Translation Studies has also highlighted potential conflicts between academic degree and vocational training when employability is emphasised and expected to be embedded in teaching (see, for example, Hubscher-Davidson and Borodo [2012], Orlando [2016], Way et al. [2010]). These concerns are acknowledged above and can, in our view, be successfully addressed. Such concerns are both logistical (how can we do it?) and ethical (should we do it, and what are the consequences if we do?). This combination of logistical and ethical challenges is also apparent in relation to the academic staff involved. Just as students' curricula are already densely packed, academic staff workloads are likely to be intense, and it is unlikely that the sort of activities for which we are arguing can be quantified neatly in workload models or recognised in existing criteria to promote, recognise or reward staff. Should the ethical head of school request or require such engagement from staff, then? Even beyond considerations of capacity, adopting this ethos also means that staff must typically work with a range of others outside their academic comfort zone. Rather than being the subject expert, this ethos means engaging with constant changes in the industry and wider world, and committing to ongoing self-development. It also means that knowledge is likely to be co-created with students. Staff thus need a broad and evolving set of skills, some of which our students master well beyond our own competence (e.g. knowledge of a particular language pair/direction, use of a tool or 
experience of a commercial sector before or beyond their studies). Such co-creation can be hard and academics themselves are unlikely ever to have had any training in this. Key to success here are the support of colleagues who are also engaged in the approach (the ED role and the personal commitment and drive of the office holder have been critical at UEA), understanding of the need to develop strategies for self-care and resilience, and a willingness to keep learning. These requirements raise broad questions of responsibility and judgment for staff just as they do for students.

From the outset, staff involved in embedding employability in our translating and interpreting courses raised ethical concerns around professional provision, concerns which are also well represented in academic scholarship around requirements relating to professional practice (e.g. Brew 2003; Schön 1995). Two important challenges involved in enabling current students to obtain real-world experience are (i) the danger of undercutting or undermining existing professional translators and interpreters, not least our own alumni; and (ii) the risk we deliver training on behalf of employers with deep pockets who can or should do this themselves. Such challenges raise broad ethical questions of power and exploitation. Solutions are various, but include careful vetting and monitoring of industry partners, building long-term mutually beneficial relationships, and limiting student work to projects that would not otherwise receive funding, such as translation for small charities, third sector organisations and local businesses which could not otherwise afford language services. These are complex questions which need ongoing attention and ethical judgement on the part of staff. Some colleagues have raised ethical concerns regarding cooperation with certain language service providers, for example, arguing that care is needed when working with an industry some of whose practices can be unethical. Arguably the increasing dominance of such practices is precisely why it might be considered ethical for universities to engage 
strongly with employability, because if students do not have the opportunity to reflect and develop skills and confidence in relation to ethical behaviour before they reach a workplace setting where their livelihood depends on it, they may only encounter profoundly challenging ethical questions when they have neither time nor unbiased support to meet them effectively. Considering the ethical aspects relating to employability also goes some way to addressing the concerns of some colleagues who raise the possibility that some students may not want to join the workforce or consider employability while at university. Engaging with the ethics, as well as an ethos, of employability can begin profound and intellectually stimulating discussions about what a modern university is for and broad questions of ethical behaviour in relation to interpreting and translation practice.

Interviewees identified cases where the embedding of employability throughout their studies served them in advancing the reasoning behind their ethical decision making as interns and employees in the industry. First, in relation to the heavy workload demands which are standard in the translation sector:

I was asked to translate much more text than I can over a weekend. I can't use magic and really want to help them but it is impossible and that was a dilemma and makes me learn about setting boundaries about what is possible.

(Postgraduate student intern in a translation company)

A second case relates to challenging the ethical decision-making often inherent in translation work:

I worked a lot for the hospitality industry and we managed a lot of Arabic translations for luxury hotel brands which covered alcohol and a luxury lifestyle. We had the issue of not offending the linguists working on the texts and also not offending the target audience. All this with pressure from the client, and colleagues needing to 
see the job completed on time for financial reasons, and not seeing the importance of the go-between cultural work we were doing.

(Established transcreation account manager in a large agency)

In such comments, we can see that the ethical challenges involved in engaging with employability as an ethos, across and beyond the curriculum, can be precisely where there is a positive - indeed ethical - impact. In other words, the ethically challenging is ethically beneficial. Especially once they find themselves in the professional context, graduates understand that employability should be embedded as an ethos because it enhances the academic content they have studied. For example, one graduate stressed the complex interrelation of training in subtitling skills, ethical reflection on translation decisions, understanding of professional contexts and the impact of translation in real-world contexts: Awareness of translation decisions and their potential consequences has been relevant when working with a series of audiovisual interviews at the moment. How do I translate language relating to mental illness for example, how important is what the client wants versus respecting sensitivities around certain terms?

Our experience of embedding employability as an ethos has convinced us that the value of the approach is intensely apparent in the ethically challenging aspects of professional practice. In this sense, failing to engage with employability could even be seen as unethical as, if we do not, graduates will have to confront such challenges and learn skills of judgement and ethical decision-making once they are in the workplace without the surrounding support and safe critical space of the university.

\section{Conclusion}


Although the necessity to embed employability-related activities within translator/interpreter training is widely recognised in the Higher Education sector, the modalities of this integration are not as straightforward as one may think. As Yorke and Knight (2006) pointed out, there is no 'one size fits all model', and what may work in one university may encounter irresolvable issues in another. The academic team teaching UEA's translation and interpreting courses have developed an employability ethos based on a diverse range of activities, in order to cover as many necessary skills and steps in career development as possible: giving the chance to acquire semi-professional experience within modules, teaching highly technical skills such as the use of sector-specific software (CAT tools, interpreting booths and equipment, and subtitling tools), or helping students realise the range of professions available to them, as well as what values and skill-sets these professions entail (e.g. via events, trips and talks). The cornerstone of this employability ethos is complementarity, between the various initiatives within the School, but also with those organised centrally by UEA's Careers Services, such as one-to-one career guidance appointments which provide students with invaluable advice from career-specialists.

As has been considered, proposing innovative activities is not without challenges. However, many of these can be overcome by demonstrating ourselves the flexibility that we would like to see in our students whether this be teaching in unfamiliar ways, embracing new subject areas, or investing considerable time in developing fruitful relationships with, inter alia, organisations and individuals delivering translation and interpreting services, and alumni. Nonetheless, any employability programme should always be considered a work in progress. For example, the complementarity mentioned above partly relies on students attending employability events and talks. Yet, engagement with these events tends not to be as high as expected on some occasions, and more work needs to be done on communicating their 
benefits to students effectively. Equally, ensuring that students do draw links between the skills they are developing in their courses and their commercial applications is an aspect which requires explicit reflective exercises. As an alumnus pointed out: "I learnt skills which didn't seem useful at the time but are of great benefit now in my role as a translator". Throughout the survey, respondents showed great insight into what they have taken away from their courses. To address the need for current students to be aware of this transfer potential before they graduate, on top of the reflective reports required in modules such as TWE, the School has developed an employability Portfolio scheme which consists of undergraduate students sending regular reflective reports on one academic and one nonacademic activity to their academic adviser, followed by a discussion between adviser and advisee. This scheme has been running for less than two years and it is too early to tell whether it will help set students further apart in written applications and interviews. The scheme is part of an overall programme which needs constant monitoring and evaluation, to ensure that as many students as possible leave university with the kind of platform required to become rounded professionals as communicated by this alumna commenting on her experience of various activities at UEA: "All in some measure helped me to decide what to do, workshops for evaluating myself, classes for technical skills, year abroad for confidence and maturing, and internships for getting my foot in the door". 


\section{References}

Brew, A. (2003) 'Teaching and research: New relationships and their implications for inquirybased teaching and learning in higher education', Higher Education Research and Development, 22 (1), 3-18

Drugan, J. (2013) Quality in Professional Translation. London/New York: Bloomsbury.

Green, W., Hammer S., and Star C. (2009) 'Facing up to the challenge: why is it so hard to develop graduate attributes?', Higher Education Research \& Development 28 (1): 17-29.

Guillot, M.N. (2006) ‘Translation work experience: the UEA way’ [PowerPoint presentation]. LLAS (Centre for Language, Linguistics and Area Studies), Teaching Translation. University of Swansea, Wales, 20 January 2006.

Guillot, M.N. (2014) 'Cross-cultural pragmatics and translation: the case of museum texts as interlingual representation'. In J. House (ed.) Translation: A Multidisciplinary Approach. Basingstoke: Palgrave Macmillan (Advances in Linguistics Series), 73-95.

Hubscher-Davidson, S. and Borodo, M. (eds.) (2012). Global Trends in Translator and Interpreter Training: Mediation and Culture. London: Bloomsbury.

Kearns, J. (2008) 'The academic and the vocational in translator education'. In J. Kearns (ed.) Translator and Interpreter Training. Issues, Methods and Debates, London, Continuum: 184214. 
Kember, D., Leung, D., and Ma, R. (2007) 'Characterizing learning environments capable of nurturing generic capabilities in higher education', Research in Higher Education 48 (5): 609632.

Kenny, D. (1999) 'CAT tools in an academic environment: What are they good for?' Target. International Journal of Translation Studies, 11 (1): 65 -82.

Kumar, A. (2007) Personal, Academic and Career Development in Higher Education. SOARing to Success. Abingdon and New York, Routledge.

Mitchell-Schuitevoerder, R. (2010) 'A project-based methodology in translator training', in Way, C., Vandepitte, S., Meylaerts, R., and Batłomiejczyk, M. (eds.) (2013) Tracks and Treks in Translation Studies: Selected Papers from the EST Congress, Leuven 2010. Amsterdam/Philadelphia: John Benjamins, 127-142.

Nulty, D. D. (2008) 'The adequacy of response rates to online and paper surveys: What can be done?' Assessment and Evaluation in Higher Education 33 (3): 301-314.

Orlando, M. (2016). Training $21^{\text {st }}$ Century Translators and Interpreters: At the Crossroads of Practice, Research and Pedagogy. Berlin: Frank \& Timme.

Peverati, C. (2013) 'Translation in modern language degree courses', InTRAlinea 15, [Online] http://www.intralinea.org/archive/article/translation_in_modern_language_degree_courses [Accessed 25 April 2016]. 
Pym, A. (2009) 'European Master in translation - possible contributions from research', contribution to a panel discussion at the European Masters in Translation Network $1^{\text {st }}$ Meeting. Brussels, 8 December, [Online] http://usuaris.tinet.cat/apym/online/training/2009_EMT.pdf [Accessed 25 April 2016].

Schön, D. A. (1995) 'The new scholarship requires a new epistemology,' Change 27 (6): 2634.

University of East Anglia (2011) The University of East Anglia Corporate Plan 2012-2016.

[Online] https://www.uea.ac.uk/documents/3154295/0/UEA+Corporate+Plan+20122016.pdf/271f7944-1e5d-441c-bc27-9bbaa661e856 [Accessed 1 May 2016].

Way, C., Vandepitte, S., Meylaerts, R., and Batłomiejczyk, M. (eds.) (2013) Tracks and Treks in Translation Studies: Selected Papers from the EST Congress, Leuven 2010. Amsterdam/Philadelphia: John Benjamins.

Yorke, M. (2006) Employability in Higher Education: what it is - what it is not. Learning and Employability Series 1. York: The Higher Education Academy.

Yorke, M. and Knight, P.T. (2006) Embedding Employability into the Curriculum. Learning and Employability Series 1. York: The Higher Education Academy. 